\title{
Rounding of pumice clasts during transport: field measurements and laboratory studies
}

\author{
Michael Manga • Ameeta Patel • Josef Dufek
}

Received: 24 December 2009 / Accepted: 4 September 2010 /Published online: 30 September 2010

(C) The Author(s) 2010. This article is published with open access at Springerlink.com

\begin{abstract}
Volcanic clasts in many pyroclastic density current deposits are notably more round than their counterparts in corresponding fall deposits. This increase in roundness and sphericity reflects different degrees of comminution, abrasion and breakup during transport. We performed experimental measurements to determine an empirical relationship between particle shape and mass loss caused by particle-particle interactions. We consider, as examples, pumice from four volcanoes: Medicine Lake, California; Lassen, California; Taupo, New Zealand; Mount St Helens, Washington. We find that average sample roundness reaches a maximum value once particles lose between $15 \%$ and $60 \%$ of their mass. The most texturally homogeneous clasts (Taupo) become the most round. Crystal-rich pumice abrades more slowly than crystal-free pumice of similar density. Abrasion rates also decrease with time as particles become less angular. We compare our experimental measurements with the shapes of clasts in one of the May 18, 1980 pyroclastic density current units at Mount St Helens, deposited 4-8 km from the vent. The measured roundness of these clasts is
\end{abstract}

Editorial responsibility: J.D.L. White

Electronic supplementary material The online version of this article (doi:10.1007/s00445-010-0411-6) contains supplementary material, which is available to authorized users.

M. Manga $(\bowtie) \cdot$ A. Patel

Department of Earth and Planetary Science,

University of California, Berkeley,

307 McCone Hall,

Berkeley, CA 94720-4767, USA

e-mail: manga@seismo.berkeley.edu

J. Dufek

School of Earth and Planetary Sciences, Georgia Tech,

Atlanta, GA, USA close to the experimentally determined maximum value. For a much smaller deposit from the 1915 Lassen eruption, clast roundness is closer to the value for pumice in fall deposits and suggests that only a few volume percent of material was removed from large clasts. In neither field deposit do we see a significant change in roundness with increasing distance from the vent. We suggest that this trend is recorded because much of the rounding and ash production occur in proximal regions where the density currents are the most energetic. As a result, all clasts that are deposited have experienced similar amounts of comminution in the proximal region, and similar amounts of abrasion as they settle through the dense, nearbed region prior to final deposition.

Keywords Ash · Comminution · Abrasion · Pyroclastic density current $\cdot$ Rounding $\cdot$ Pumice

\section{Introduction}

Particles both collide with and slide past each other within pyroclastic density currents. This will lead to abrasion and comminution of clasts (e.g., Walker 1981) and the shattering of clasts if collisions are energetic enough (e.g., Schwarzkopf et al. 2007). Abrasion during transport is expected to lead to a progressive rounding of clasts whereas breakup will increase their angularity. Rounding of pumice clasts is often interpreted as evidence for transport in pyroclastic density currents (e.g., Wilson and Hildreth 1998), hence clast shape may preserve information about the transport processes within currents. Particle roundness is expected to increase with transport distance in density currents, and significant rounding of clasts is often found in distal deposits (e.g., Calder et al. 2000) and in pumice lobes (e.g., Pittari et al. 2005). In some deposits there is enough 
variability in clast roundness and shape to distinguish among genetic processes and elucidate transport dynamics (Dellino and Volpe 1996). Nevertheless, Murai (1961) found no "remarkable variation in roundness values with distance from the source" (Murai 1961).

Comminution and abrasion of large pumice clasts are expected to occur within pyroclastic density currents owing to both collisions and frictional interactions among particles. Evidence of abrasion is preserved not only in the shapes of pumice clasts, but also at the scale of single crystals (Freundt and Schmincke 1992; Taddeucci and Palladino 2002). Reworked volcanic deposits also show decreased roughness and decreased shape complexity compared with juvenile clasts (Carey et al. 2000) highlighting the importance of transport in shaping grains. Dufek and Manga (2008) performed numerical simulations of pyroclastic density currents to quantify the amount of ash expected to be produced by frictional and collisional interactions among particles. The rate of ash production was based on lab measurements of ash produced by frictional interactions (Cagnoli and Manga 2004) and ash produced by collisions (Cagnoli and Manga 2003; Dufek and Manga 2008). Dufek and Manga (2008) conclude that a few to several tens of percent of the mass of large $(>\mathrm{cm}$ size) particles should be comminuted into ash-sized particles prior to deposition, with roughly equal amounts produced by collisions and frictional interactions.

Here we are interested in the relationship between the shape of pumice clasts and the amount of mass that is transferred into smaller particles during transport of the clasts. We first determine experimentally an empirical relationship between the shape of particles and the amount of mass they lose owing to clast-clast interactions. We then use the same metric of shape to characterize pumice in pyroclastic density current deposits at Mount St Helens, Washington, USA and Lassen, California, USA in order to estimate the amount of comminution of large clasts during transport, from the vent to their final deposition.

\section{Experimental methods}

In order to understand how shape evolves during comminution we first performed laboratory measurements in which we characterize the shape of pumice clasts as they abrade through particle-particle interactions. We consider samples from four eruptions: pumice from the AD 181 Taupo Ignimbrite Veneer deposit, New Zealand (from leeside lenses within the main body of the deposit (layer 2) located at $12-15 \mathrm{~km}$ from the inferred source vent; azimuth from source is between 105 and 115 degrees east); falldeposit pumice from the $\sim 850$ BP Glass Mountain eruption at Medicine Lake volcano, California; pumice from the
May 18, 1980 Mount St Helens eruption obtained from a "middle sequence" pyroclastic flow deposit (categorization of Criswell 1987); pumice from the May 22, 1915 eruption at Mount Lassen, California, unit pf 22 of Christiansen et al. (2002). For Medicine Lake and Mount Lassen experiments, our starting materials are fall-deposit pumice. These two sets of samples should preserve the roundness of natural clasts that exit the volcanic conduit. For the rounding experiments with St Helens and Taupo pumice, we did not (at the time) have access to fall-deposit pumice so we mechanically created centimeter-size fragments from decimeter-size clasts by splitting them with a chisel. We then selected groups of similar-sized clasts that lacked significant tool marks.

Figure 1 shows photographs of typical clasts of each type of pumice. Figure 2 shows representative microscope images of each type of pumice. Both Lassen and St Helens pumice have large (mostly plagioclase) phenocrysts that occupy a volume fraction of about 20-25\% (Clynne 1999; Criswell 1987, respectively). Texturally, the Taupo pumice samples are the most homogenous whereas Medicine Lake pumice exhibits a greater range of vesicularity and texture (including tube pumice). Taupo and Medicine Lake pumice have crystal volume fractions of less than $1 \%$.

The analysis and characterization of particle shape has a long history. The angularity of large clasts is usually noted in a qualitative sense, with expressions such as "angular", "subangular", "subrounded", and "rounded" used when characterizing natural field deposits, or in a semiquantitative manner by comparison with comparative charts (e.g., Krumbein 1941; Powers 1953; Murai 1961). Digital

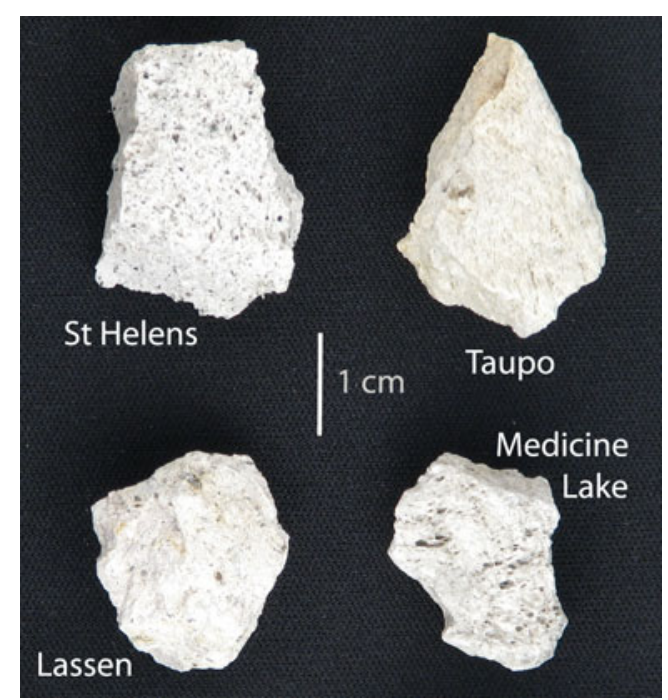

Fig. 1 Examples of pumice clasts for the four starting materials. Clockwise from upper left: St Helens, Taupo, Medicine Lake, Lassen. Values of $R$ are $0.71,0.73,0.86$, and 0.77 , respectively. The two clasts in the top row were created by breaking much larger clasts in the lab. Clasts in the bottom row are from air-fall deposits 
Fig. 2 Examples of thin section images from pumice clasts for the four starting materials. Clockwise from upper left: $\mathrm{St}$ Helens, Taupo, Medicine Lake, Lassen. The number above each scale bar is in microns. All images are SEM images except for Lassen which is taken with transmitted light on a petrographic microscope

\section{St Helens}
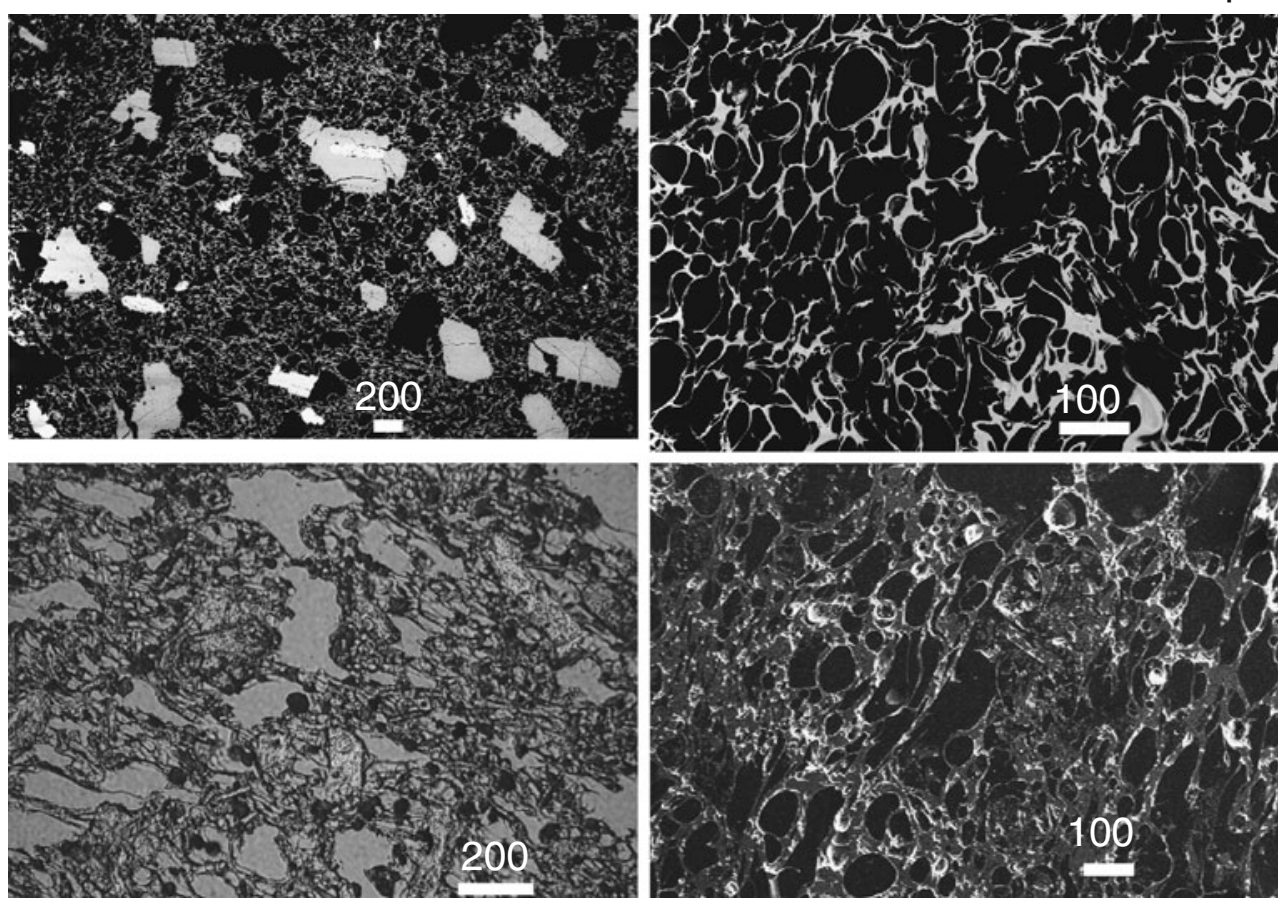

Lassen

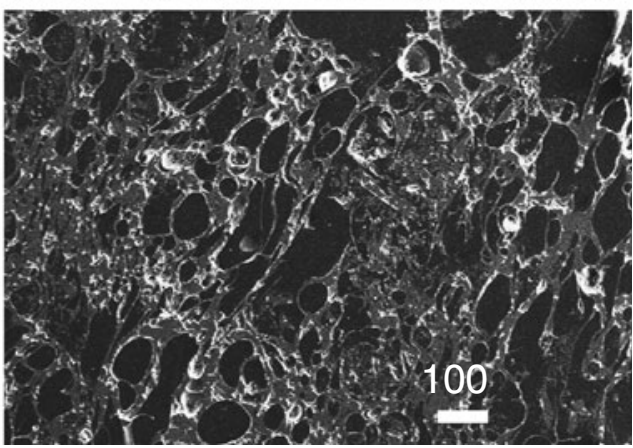

Medicine Lake cameras and analysis tools make a quantitative measure straightforward (e.g., Dellino and Volpe 1996).

In order to characterize the shape of the particles we took 5.1 megapixel photographs of the particles with a digital camera. Particles were placed on a dark background so that their boundaries could be digitally recognized. Figure 3 shows an example raw image of the particles and the thresholded, processed images used for subsequent image analysis. We consider only two-dimensional characterization of particles and thus lose information about their threedimensional shape (e.g. sphericity). While quantitative three dimensional shape analysis is possible, for example by laser scanning (e.g. Hayakawa and Oguchi 2005), it is prohibitively time consuming to perform for multiple clasts. We do, however, use the same image analysis approach and sample characterization for field deposits and hence we are at least self-consistent in our empirical analysis.

Here, we use as a metric for particle shape the measure

$R=\frac{4 \pi A}{P^{2}}$

where $P$ is the perimeter of the particle and $A$ is the crosssectional area, both identified from the two-dimensional image. This measure is sometimes called the Shape Factor (e.g., Shea et al. 2010). With this definition, a circular disk (projection of a sphere) has $R=1$ and all other shapes have $R$ less than 1 , decreasing with increased shape complexity and particle elongation. The metric $R$ is a two-dimensional analogue to the sphericity defined by Wadell (1932). As we consider two-dimensional images of particles, and spheres are three-dimensional objects, we will hereafter use the term roundness to describe $R$. We emphasize that $R$ includes effects that are normally separated into roundness (sharpness of corners) and form (Barrett 1980).

Both $P$ and $A$ are estimated from counting pixels that define the particle perimeter and area, respectively. Choosing pixels that define the perimeter requires some care. We constructed a perimeter by connecting every fourth pixel that lies along the perimeter of each clast. This approximation includes small-scale features while excluding spurious rough edges from pixelization (Durian et al. 2007; Shea et al. 2010). This wavelength of smoothing was found to best represent circular shapes compared to their theoretical value $(R=1)$. In order to assess the image quality and accuracy of the thresholding algorithm, we use two procedures. First, we varied the thresholding parameter used to distinguish particles from the background over a wide range of values. We ensured that no spurious dust was included nor part of particles removed by the thresholding algorithm. Second, we placed $1.91 \mathrm{~cm}$ and/or $1.27 \mathrm{~cm}$ diameter spheres next to the particles to serve as reference shapes. Figures 3 and 4 show images and processed images taken in the lab and field, respectively. We attempted to ensure that $R$ for the spheres was within $2 \%$ of 1 ; there are a couple exceptions (one was selected for Fig. 3) where the error is larger as a result of poor illumination near the edge of the image. $R$ can slightly exceed 1 because we include only every fourth pixel when defining the perimeter, but we include all pixels 
a)

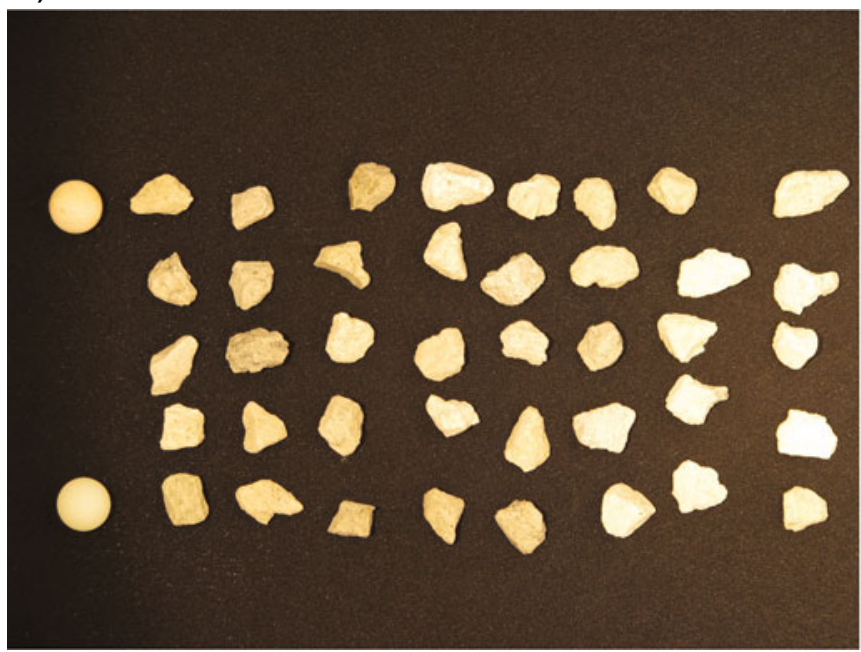

c)

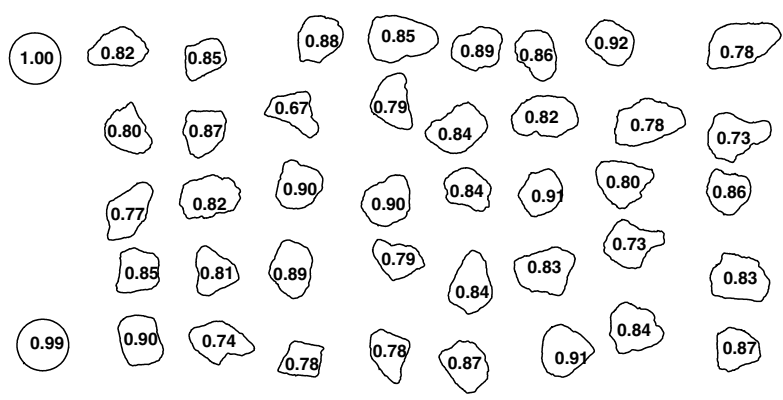

Fig. 3 a and b Show photographs of clasts before and after the rounding experiments, respectively, for pumice from Medicine Lake $(12.5+\mathrm{mm}$ category in Table 1$)$. c and $\mathbf{d}$ Are processed images

when defining the area. This bias is greatest for small particles, and can be reduced by increasing photograph resolution. A MATLAB script for performing this analysis is included in the electronic supplement.

To assess the reliability of measuring $R$ we made repeat measurements of the same set of 20 pumice particles from Medicine Lake (12.5+ mm size class). The samples were placed on a flat surface, photographed, and $R$ was measured. The samples were then removed and replaced on the surface and photographed again. Figure 5 shows the mean value of $R$ and the standard deviation for 8 trials. The mean value of the mean of $R$ is $0.828 \pm 0.009$. In contrast, the standard deviation of $R$ among clasts in a given image is much larger, typically about 0.06 , and $R$ for individual clasts ranged from as low as 0.68 to as high as 0.94 . This test shows that the mean value of $R$ for a set of clasts is well determined by a single photograph. This test also shows that the uncertainty in the mean of $R$ is much less that the variability of $R$ among clasts.

To determine the relationship between mass loss and $R$, we abraded particles in a rock tumbler. The rock tumbler was a cylindrical container $8 \mathrm{~cm}$ long with a diameter of b)

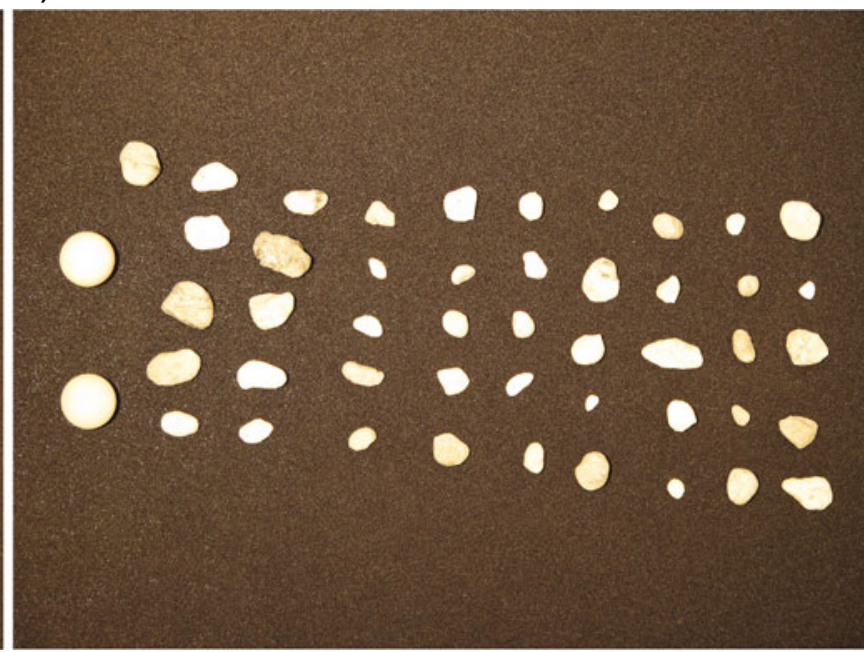

d)

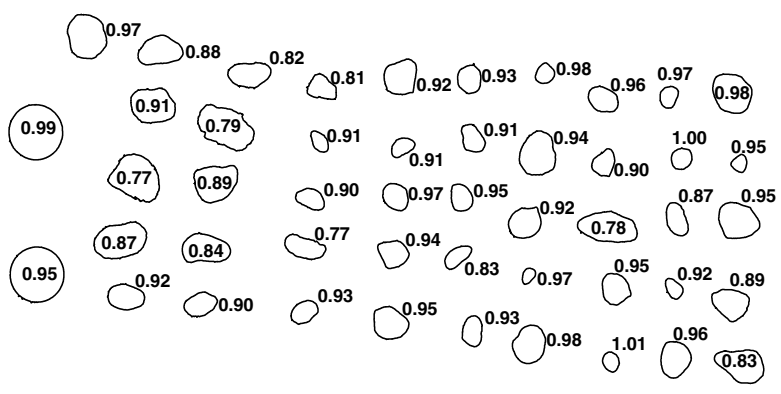

corresponding to (a) and (b), respectively, and the numbers shown are calculated values of roundness $R$. Spheres in these images have diameters of $1.27 \mathrm{~cm}$

$8 \mathrm{~cm}$. The rotation rate was 55 rotations per minute for all experiments. Periodically, at time intervals that ranged from $20 \mathrm{~s}$ to as long as $3 \mathrm{~h}$ depending on how fast the particles were changing shape, we removed and photographed the particles. Loose ash was removed prior to obtaining each photograph and mass measurement. The size distribution and a photograph of this ash for the Medicine Lake samples are published in Dufek and Manga (2008). To assess the role of ash on the evolution of roundness, we performed one complementary experiment on Medicine Lake pumice in which we fixed the mass proportion of ash present in the rock tumbler to $20 \%$ (with a small amount of additional ash formed owing to comminution of the large particles between measurements). The nature of particle-particle interactions in a rock tumbler is undoubtedly different from that in pyroclastic density currents, and the size distribution of comminuted porous particles may be sensitive to the mechanical forces that break the particles (Bevilacqua and Ferrara 1996). Unfortunately, controlled experiments at conditions similar to those in natural situations are impractical. In the numerical simulations presented in Dufek and Manga (2008) and shown later in this paper 
a)
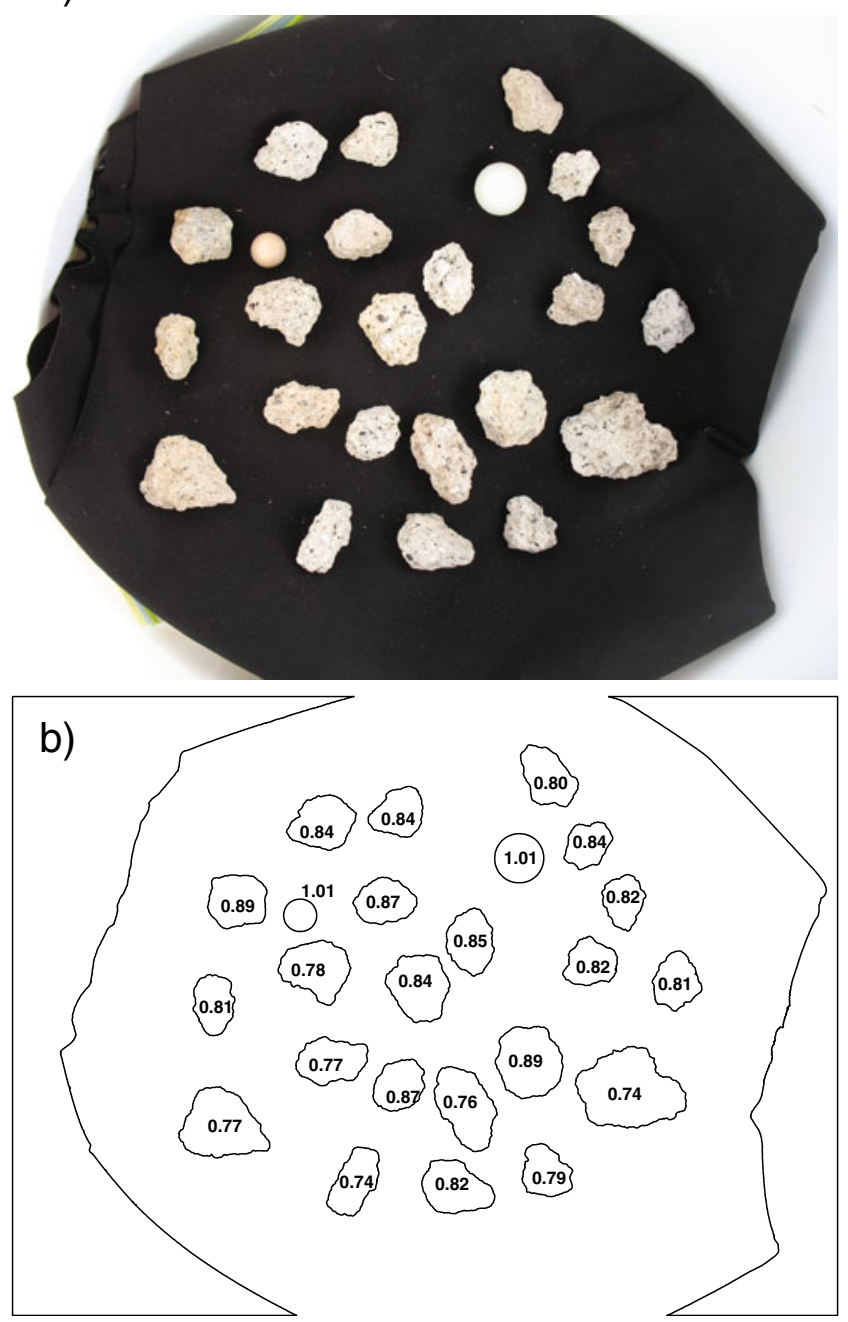

Fig. 4 a Photo of pumice at Lassen taken in the field. b Processed image corresponding to (a), and the numbers shown are calculated values of roundness $R$. Spheres in the image have diameter of $1.27 \mathrm{~cm}$ and $1.91 \mathrm{~cm}$

(Fig. 12), however, the ash-production models are based on experiments with individual collisions (Cagnoli and Manga 2003; Dufek and Manga 2008) and dense shear flows (Cagnoli and Manga 2004) which capture the particle dynamics when collisions and frictional interactions dominate, respectively. The goal of the present experiments is not to revise these previous estimates of comminution rates, but instead is to relate the mass loss that results from clast interactions to a measureable property of the clasts, namely their shape as characterized by $R$.

Table 1 lists some of the properties of the pumice clasts used in the experiments, including their size and density. Values in the columns labeled "start" are values before particles experienced any rounding. Values in the columns labeled "end" are values after the final rounding step. All reported uncertainties are one standard deviation of the mean for each set of clasts and characterize the variability from clast to clast rather than measurement uncertainty (which is much smaller). Density was measured by weighing the particles in air and then weighing the same particles coated in wax and immersed in water. This density measurement was only done on the end products because the wax used to coat the particles would have influenced their comminution. All particles were weighed together; hence the reported density is the mean for each set of particles.

We note that there are many other measures of particle shape that have been used and simultaneous consideration of multiple measures of shape potentially offers many advantages (e.g., Dellino and La Volpe 1995). Other approaches that lend themselves well to straightforward analysis of digital images include Fourier shape analysis (e. g., Schwarcz and Shane 1969) and fractal and multifractal shape analysis (e.g., Orford and Whalley 1983; Dellino and Liotino 2002; Maria and Carey 2007). The metric we adopt, Eq. 1, captures some of the effects of both shape and roughness so it is most useful when particles begin with an angular equant shape. Most importantly, we found that it varies monotonically as mass is lost and hence it offers a useful, albeit empirical, way to relate field deposits and lab measurements. Finally, the test in Fig. 5 shows that $R$ is reliably determined from a single photograph.

\section{Results and interpretations}

We first consider the effect of particle interactions on the evolution of shape, and second on the rate of mass loss.

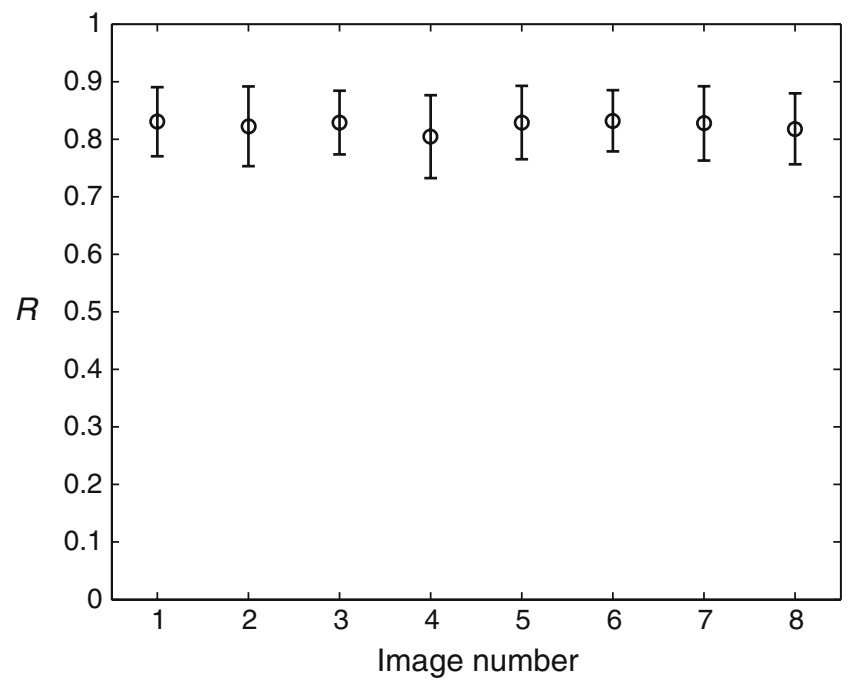

Fig. 5 Mean value of $R$ and its standard deviation for 8 repeat measurements of the same 20 pumice clasts from Medicine Lake, $12.5+\mathrm{mm}$ size class (Table 1). Between each measurement particles were removed and replaced before being photographed 
Table 1 Properties of the pumice clasts used in the rounding experiments. "Start" indicates values before any rounding; "end" indicates values after all the rounding steps are complete. Quoted uncertainties are one standard deviation

\begin{tabular}{|c|c|c|c|c|c|c|c|c|c|}
\hline Sample & $\begin{array}{l}\text { Start } \\
\text { mass }(\mathrm{g})\end{array}$ & $\begin{array}{l}\text { \# of } \\
\text { clasts } \\
\text { start }\end{array}$ & $\begin{array}{l}\text { Start } \\
\text { roundness }\end{array}$ & $\begin{array}{l}\text { Start area } \\
\left(\mathrm{cm}^{2}\right)\end{array}$ & $\begin{array}{l}\text { End } \\
\text { mass }(g)\end{array}$ & $\begin{array}{l}\# \text { of } \\
\text { clasts } \\
\text { end }\end{array}$ & $\begin{array}{l}\text { End } \\
\text { roundness }\end{array}$ & $\begin{array}{l}\text { End area } \\
\left(\mathrm{cm}^{2}\right)\end{array}$ & $\begin{array}{l}\text { End density } \\
\left(\mathrm{g} / \mathrm{cm}^{3}\right)\end{array}$ \\
\hline MSH split in lab & 98.530 & 20 & $0.74 \pm 0.06$ & $6.45 \pm 1.07$ & 23.038 & 20 & $0.90 \pm 0.05$ & $2.32 \pm 0.48$ & 0.74 \\
\hline Taupo split in lab & 52.132 & 20 & $0.69 \pm 0.06$ & $6.61 \pm 1.35$ & 12.176 & $19^{\mathrm{a}}$ & $0.95 \pm 0.04$ & $1.90 \pm 1.26$ & 0.51 \\
\hline Lassen airfall & 172.012 & 20 & $0.78 \pm 0.06$ & $5.58 \pm 1.65$ & 132.784 & $36^{\mathrm{b}}$ & $0.87 \pm 0.05$ & $2.34 \pm 2.07$ & 2.0 \\
\hline $\begin{array}{l}\text { Medicine Lake } \\
12.5+\mathrm{mm} \text { airfall }\end{array}$ & 65.392 & 40 & $0.82 \pm 0.05$ & $2.92 \pm 0.99$ & 40.918 & $50^{\mathrm{b}}$ & $0.91 \pm 0.05$ & $1.65 \pm 0.80$ & 0.87 \\
\hline $\begin{array}{l}\text { Medicine Lake } \\
8-9.5 \mathrm{~mm} \text { airfall }\end{array}$ & 18.385 & 40 & $0.83 \pm 0.06$ & $1.11 \pm 0.20$ & 6.703 & $46^{\mathrm{b}}$ & $0.88 \pm 0.07$ & $0.43 \pm 0.24$ & - \\
\hline $\begin{array}{l}\text { Medicine Lake } 12.5+\mathrm{mm} \\
\text { with } 20 \% \text { ash airfall }\end{array}$ & 36.001 & 20 & $0.85 \pm 0.05$ & $2.84 \pm 0.69$ & 19.699 & $22^{\mathrm{b}}$ & $0.90 \pm 0.07$ & $1.51 \pm 0.80$ & - \\
\hline
\end{tabular}

${ }^{a}$ One clast disappeared during a 4 month hiatus in this experiment

${ }^{\mathrm{b}}$ Clasts broke up

\section{Evolution of shape}

Figure 6 shows the evolution of roundness with mass loss for the four pumice examples. Symbols are plotted at the mean value of $R$ and the error bars indicate the standard deviation. While the standard deviations are large, the mean value evolves smoothly and reaches an approximately steady value that shows little fluctuation. The large standard deviation reflects heterogeneities in initial clast shape, porosity, crystallinity, and texture - heterogeneities that are present in both samples used in lab measurements and in natural density currents. Figure 7 shows the evolution of the roundness for the ash-present experiment. The final steady value of the $R$ is the same and the evolution of $R$ with mass loss is similar.

A "steady" degree of roundness is reached after between about $15 \%$ and $60 \%$ mass loss. Lassen pumice reached a steady $R$ after the smallest amount of mass loss (see electronic supplement for data tables); for Lassen pumice we did not continue the experiments beyond $23 \%$ mass loss because reaching this amount of mass loss required a total of $22.5 \mathrm{~h}$ of abrasion in the rock tumbler (see Section 3.2). For the texturally most homogeneous pumice, Taupo, the value of $R$ is about 0.95 and this pumice also has the smallest standard deviation of $R$. For the other samples the steady value is in the range of 0.87 to 0.91 . The lack of further rounding is probably the result of two processes. First, in the case of Medicine Lake pumice, the textural heterogeneity of the clasts and bubbles influence their rounding as strength variations within clasts will lead to spatially variable abrasion and hence limit $R$. St Helens and Taupo pumice have large phenocrysts that protrude from the clasts as they round, and this lowers their roundness. Second, pumice particles broke during the experiments. In the case of Lassen pumice, the initial 20 particles ended as 36 particles. Breakage of clasts makes them less round. The breakage
Fig. 6 Evolution of clast roundness as mass is lost. Symbols are plotted at the mean roundness. Error bars indicate standard deviations. The horizontal lines indicate approximate values of the steady roundness. The starting pumice from Lassen and Medicine Lake was air-fall pumice. For St Helens and Taupo, the starting material was created by splitting larger clasts in the laboratory. Inset figure shows Lassen data

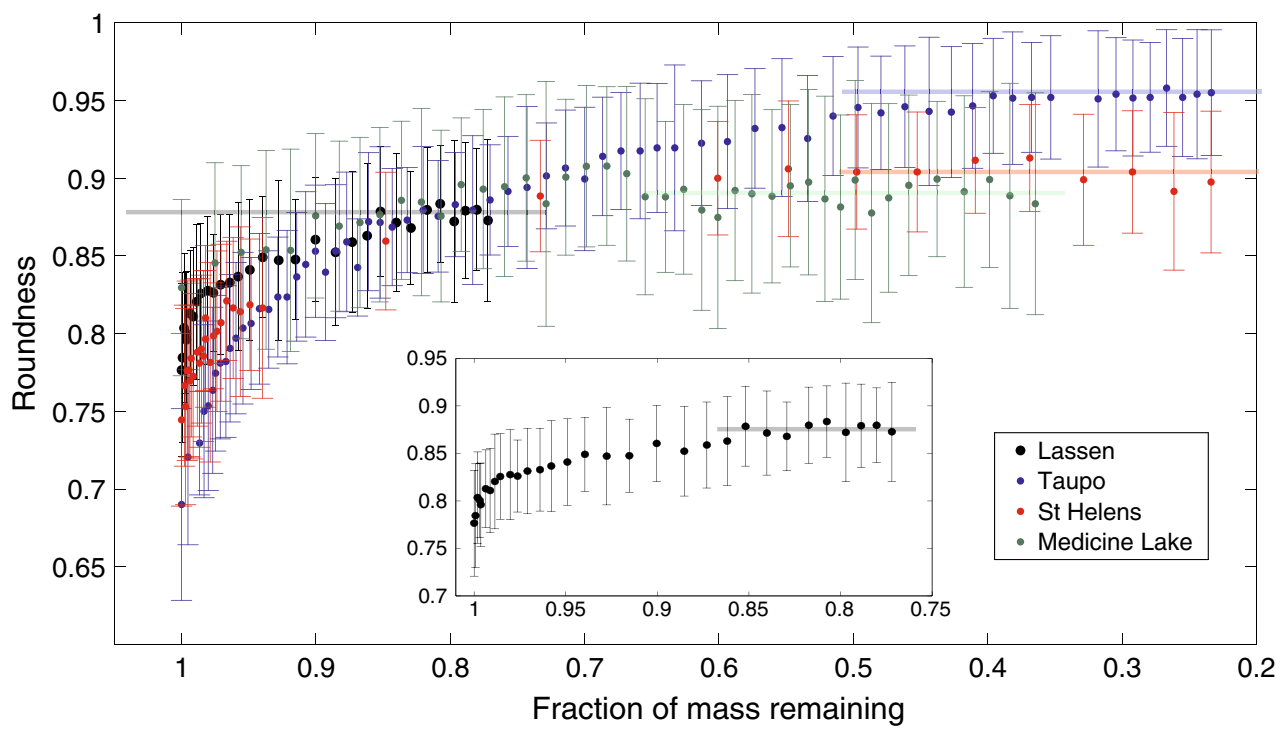




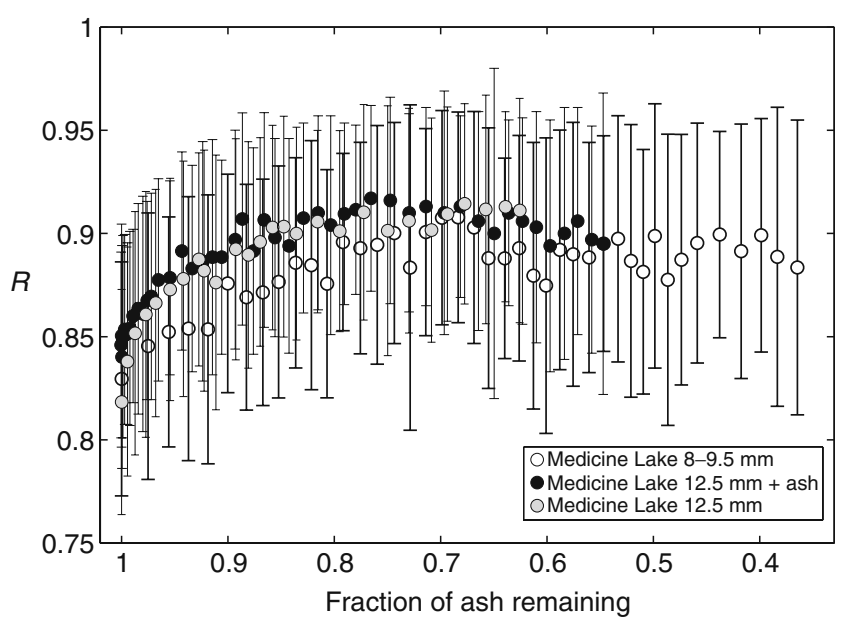

Fig. 7 Evolution of clast roundness as mass is lost for Medicine Lake pumice for three cases: all ash is removed between measurements for $12.5 \mathrm{~mm}$ pumice and $8-9.5 \mathrm{~mm}$ pumice; $20 \%$ by mass of ash is added to $12.5 \mathrm{~mm}$ pumice particles and this mass fraction is maintained after each measurement (with $20 \%$ ash)

of any one clast (a representative number for clasts that break between any two sucessive measurements), however, does not significantly affect the mean value of $R$ (see data tabulated in the electronic supplement that lists the number of clasts and mean R). This is because a decrease in $R$ of around 0.1 for the broken clast (the difference in $R$ between typical steady-state values and that for fall pumice) contributes less than 0.005 to the mean value of $R$ whereas the uncertainty in the mean of $R$ is about 0.01 (Fig. 5). Indeed the variability of $R$ once the steady value is reached is similar for clasts that do not breakup (Taupo, St Helens) as that for clasts that do breakup (Lassen, Medicine Lake).

Particle roundness at a given amount of mass fraction loss does not show a strong correlation with particle size, and the sign of the (weak) correlation is different between samples. For Taupo, Medicine Lake, Lassen and St Helens pumice, a linear fit of $R$ and clast size (measured as the square root of the cross-sectional area) at the end of each experiment gives correlations $\left(R^{2}\right)$ of $0.005,0.26,0.024$, and 0.021 , respectively. At best only a very small fraction of variability in roundness can be correlated with clast size. However, and importantly, in actual density currents this does not exclude the potential for different amounts of mass loss in different sized particles owing to dynamic particle size sorting that causes different stress and collision histories.

Rate of mass loss

Figures 8 and 9 show respectively the loss of mass and rate of mass loss $\mathrm{d} M / \mathrm{d} t$, normalized by the initial mass $M_{o}$, for the four types of pumice used in the experiments. We will hereafter refer to $M_{o}^{-1} \mathrm{~d} M / \mathrm{d} t$ as the "abrasion rate". The abrasion rate for the two crystal-rich pumice samples (Lassen, St Helens) is about a factor of 5-10 lower than that for the crystal poor samples (Medicine Lake, Taupo), at least over the first $100 \mathrm{~min}$ of the experiment. The evolution of abrasion in time is more complex. For Lassen and Medicine Lake pumice, the abrasion rate decreases monotonically with time, and for Lassen decreases by an order of magnitude as the particles lose only $30 \%$ of their mass. For the other samples, the range of abrasion rates, and the change in abrasion rate with mass loss, are not as large. For the St Helens and Taupo pumice, the abrasion rate initially decreases, but increases after about $30 \%$ and $50 \%$ mass loss, respectively. This increase does not occur for Medicine Lake pumice, which lost $64 \%$ of its mass during the experiment. The horizontal bars shown in Fig. 4 indicate the times at which $R$ reached the steady
Fig. 8 Fraction of mass remaining as a function of time spent rotating in the rock tumbler. The horizontal lines indicate the time at which $R$ stopped increasing. The gap in the Taupo data occurs where one clast went missing (see Table 1). Error bars are smaller than the symbols

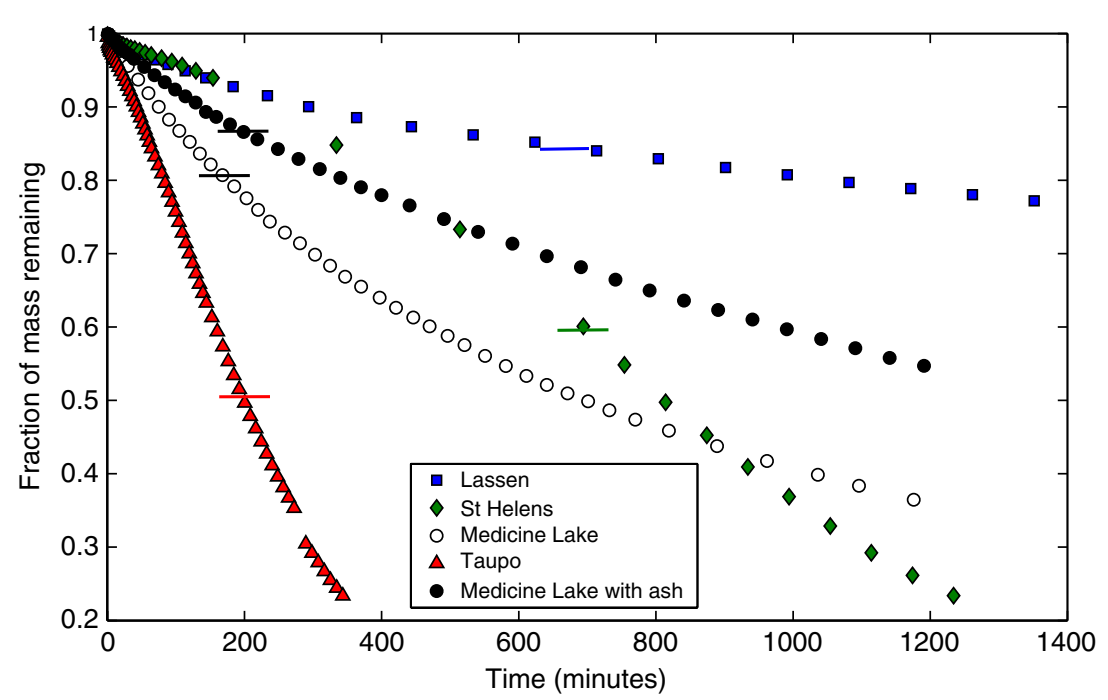


Fig. 9 Abrasion rate, $M_{o}^{-1} d M / d t$, as a function of time $(t) . M_{o}$ is the initial mass of the clasts. Error bars are smaller than the symbols

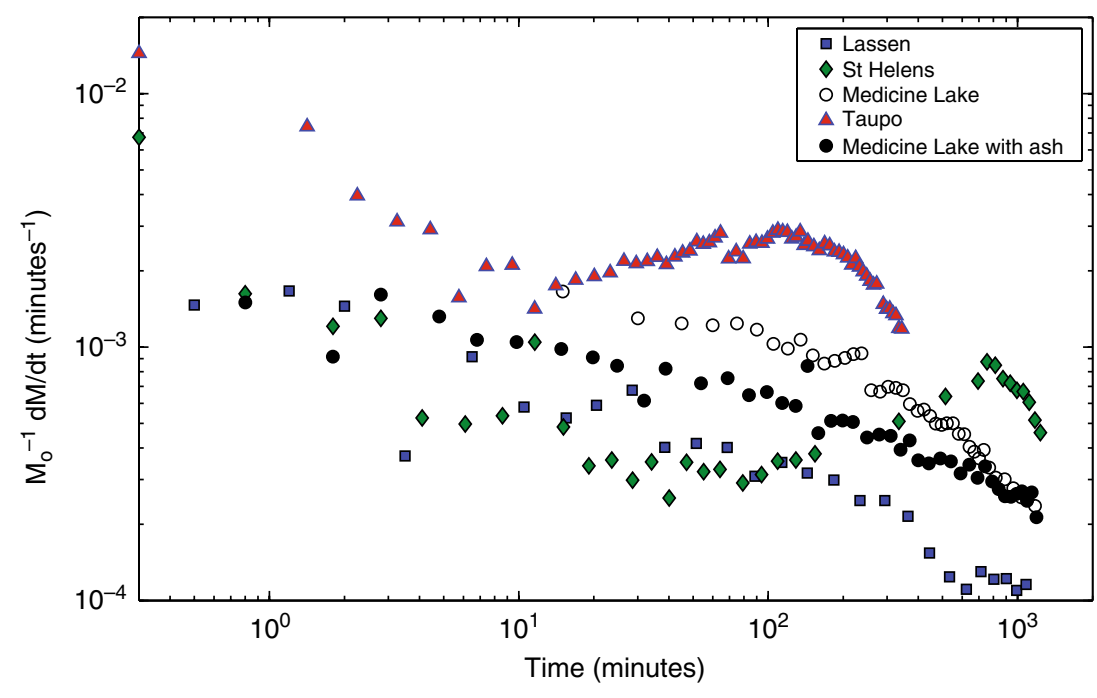

value. There is no obvious change in abrasion rate connected with $R$ reaching a steady value.

A time evolving abrasion rate is not unexpected as the shape and form of the clasts are continually evolving as the clasts are abraded. Initially, the clasts are angular and sharp corners are expected to round quickly leading to high rates of mass loss. Over time, as clast surfaces become more smooth and clasts become less angular, we might expect that the rate of mass loss by abrasion will decrease. This anticipated evolution does in fact characterize the abrasion rates at early times for all clasts, and the abrasion rate for all times for Lassen and Medicine Lake pumice. However, for long times, the abrasion rate of St Helens and Taupo pumice increases (though we note that it varies by only factors less than three). We could not identify any reason for the increases in abrasion rates for long times for these two samples.

While we did not document an effect of ash on the relationship between shape and mass loss, Figs. 8 and 9 show that the presence of ash affects the abrasion rate. The with-ash pumice loses mass about 30\% more slowly compared to the same pumice without ash. In addition, the presence of ash in real flows will affect comminution because ash influences transport of clasts (Dufek et al. 2009) and flow mechanics (e.g., Roche et al. 2005).

The particle interactions in a rock tumbler are not the same as those in the dense parts of pyroclastic density currents where abrasion is likely to dominate comminution. However, the rock tumbler does allow for differential motion between particles, the key for causing abrasion. To leading order, the mass loss scales with distance particles travel (Cagnoli and Manga 2004). The distance traveled by the outer surface of the container holding the particles is $15 \mathrm{~m} / \mathrm{min}$. If we assume mean velocities of particles $v_{p}$ are $1 / 2$ of this value, the fractional mass loss with distance is
$\frac{1}{M} \frac{\partial M}{\partial x}=\frac{1}{M} \frac{\partial M}{\partial t} \frac{d t}{d x}=\frac{1}{M v_{p}} \frac{\partial M}{\partial t}$

The measured abrasion rates of $\sim 10^{-3}$ per minute correspond to fractional mass losses of $\sim 10^{-4} \mathrm{~m}^{-1}$, or $10 \%$ per kilometer. For comparison, the measured rate of mass loss for Medicine Lake pumice in the shear flows of Cagnoli and Manga (2004) implies a similar mass losse of $\sim 30 \%$ per kilometer. The measured $10 \%$ rate of mass loss characterizes mass loss by abrasion which only occurs near the base of pyroclastic density currents and while clasts are still being transported. This does not mean that clasts transported $1 \mathrm{~km}$ from the vent will have lost $\sim 10 \%$ of their mass, as much of the transport occurs in more dilute regions of the current where particles will lose mass predominantly by collisions with one another rather than with the bed.

Putz et al. (2010) measured the abrasion rate of natural pyroclasts using a rock tumbler similar to that used in the present study. They found that mass loss increased linearly in time, as did Cagnoli and Manga (2004). In the experiments presented here, we see a similar roughly constant rate of mass loss for small mass losses (up to $\sim 10 \%$, the mass losses considered in these other studies), but then significant changes in abrasion rate with continued abrasion. A decrease in abrasion rate is expected as the least resistant parts of the clasts will be removed first. Kuenen (1956) documented a similar decrease in abrasion rate with increasing roundness for non-vesicular pebbles. Kuenen (1959) further showed that sand-size particles abrade more slowly than pebbles of the same material. For pumice Putz et al. (2010) found that the rate of mass loss increased with increasing clast size, increasing vesicularity, and increasing grain size variability. Our experiments add to this list of conclusions; in particular, 1) increasing crystallinity reduces the rate of 
abrasion, and 2) in general, increasing the roundness of clasts decreases the abrasion rate.

\section{Comparison with natural deposits}

We expect that clasts will become progressively more smooth (increasing $R$ ) until they lose enough mass to reach the near-steady roundness. Beyond this point, clasts may continue to be comminuted but our measure $R$ will no longer record this comminution. We can apply the same measurement approach to samples collected from natural pyroclastic density current deposits. We did this for two deposits, at Mount St Helens and at Mount Lassen.
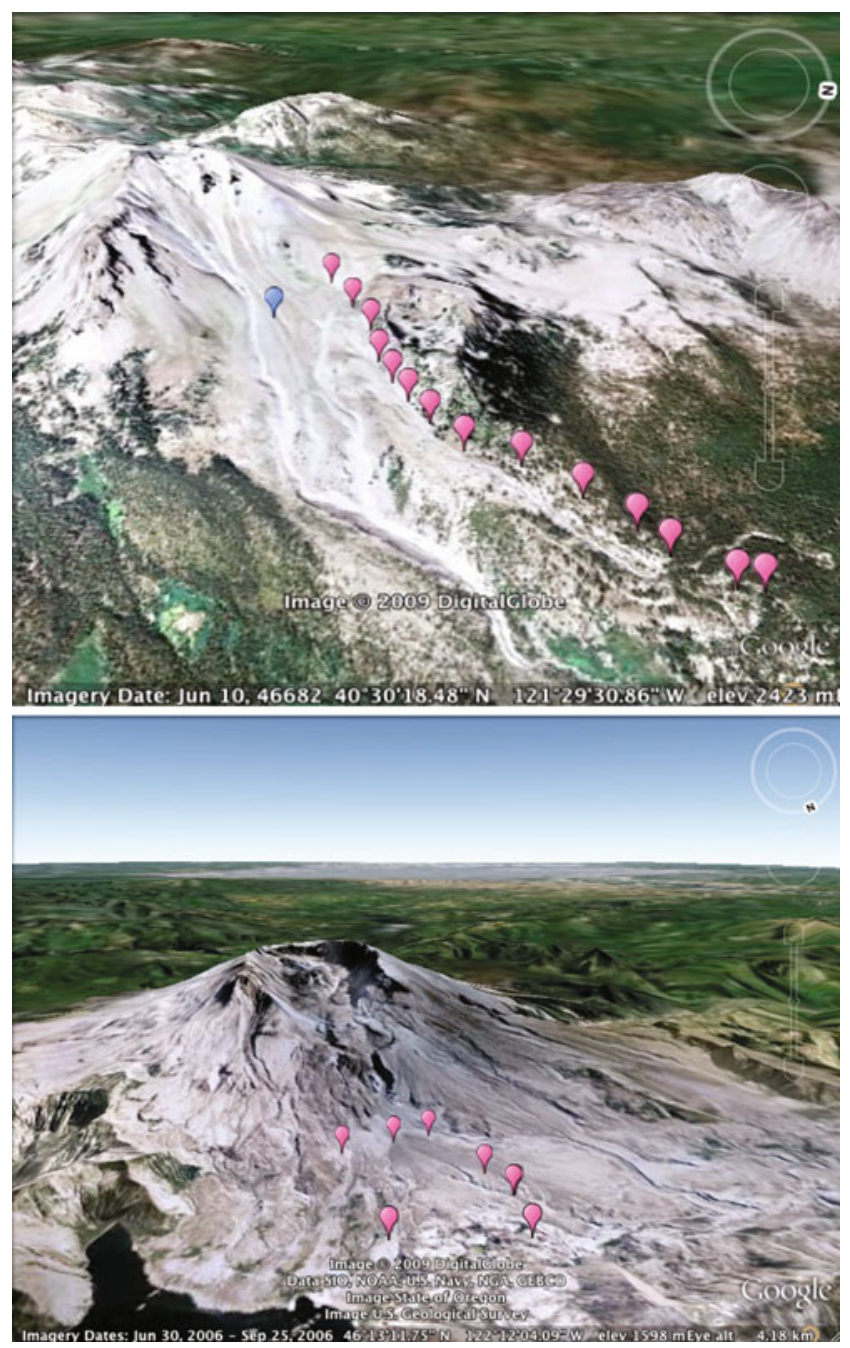

Fig. 10 Top Sample locations for rounding measurements at Lassen. Sampled unit is from the May 18, 1915 eruption, unit pf22 PF from Christiansen et al. (2002). Pink symbols are sample locations from the flow deposit and the blue symbol indicates the sample location for the air-fall deposit. Bottom Sample locations at Mount St Helens. Images created with Google Earth. Latitude, longitude and measurements of particle size and shape for each location are provided in the electronic supplement
Centimeter-sized pumice clasts, similar to those studied in the laboratory, were randomly sampled from a region of less than a couple of square meters at each site. Photographs were taken in the field by placing particles on a black background in a translucent white plastic bucket, which allowed for uniform diffuse lighting (e.g., Fig. 4). Figure 10 shows sample locations with respect to the volcanic edifices. Details of sample location (latitude, longitude, elevation) and properties of the sampled clasts are tabulated in the electronic supplement.

At Mount St Helens, we sampled one of the upper units of the middle sequence from phase IV on the May 18, 1980 eruption (chronology from Criswell 1987). We attempted to ensure that we were sampling a single flow deposit by tracing it along gullies. The deposits are vertically graded, and the pumice was sampled from the uppermost meter consisting of fines poor and discontinuous pumice lenses. Particle size distribution is reported in Hobblitt et al. (1981); about $1 \mathrm{wt} \%$ of the deposit is coarser than $1 \mathrm{~cm}$.

At Lassen we sampled unit pf22 of Christiansen et al. (2002). The grain size distribution and deposit thickness are reported in Eppler (1987). Median grain size decreases from about $4 \mathrm{~mm}$ to $1 \mathrm{~mm}$ between 2 and $5 \mathrm{~km}$ from the vent. Deposit thickness is typically a couple $\mathrm{cm}$ over these distances (comparable to the size of the clasts we analyzed) with no distinctive sedimentary structures. There is no significant change in the degree of sorting. The centimetersize clasts we study comprise about $50 \mathrm{wt} \%$ of the deposit at the sampling locations closest to the vent and less than a few percent at the most distal regions sampled.

Figure 11 shows $R$ as a function of distance from the eruptive vent. At both St Helens and Lassen there is no clear trend of increasing $R$ with increasing distance from the vent, though a higher density of sampling may be necessary to confirm this inference. Nevertheless, the value of $R$ that we measured is distinctly different from that of fall-deposit pumice, which has $R \sim 0.78$ (all three samples of pumice from fall deposits we sampled had similar values of $R$ ). Subsequent to the experiments shown in Fig. 6 we obtained photos of fall-deposit pumice from St Helens; these provide $R=0.78 \pm 0.08$. Again, the uncertainty we report and the error bars we plot do not indicate the uncertainty in our measure of shape, but the variability of $R$ from clast-to-clast; Fig. 5 shows that the mean value of $R$ is determined to about 0.01 .

We can use the experimentally-determined relationship between mass lost and roundness to estimate the amount of comminution experienced by the pumice preserved in the field deposits. Implicit in using the lab experiments to interpret deposits are 2 key assumptions: 1) the clasts at any one location have experienced similar histories and hence similar amounts of comminution, and 2) forms of agitation and particle interaction different from those in the experi- 


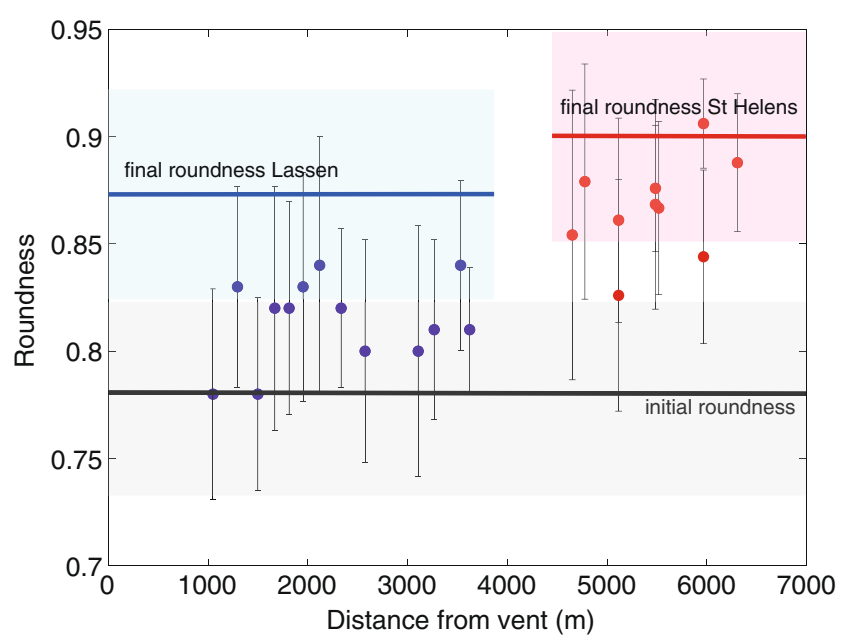

Fig. 11 Pumice clast roundness as a function of distance from the vent at Lassen (blue symbols) and St Helens (red symbols). Error bars indicate the standard deviations of roundness in each sample. Solid horizontal line indicates the roundness of air fall pumice, which is the same for Lassen and St Helens pumice. Lines surrounded by the shaded regions indicate the steady roundness and standard deviation, respectively, from the laboratory experiments (red and blue) and field measurements (grey). See Fig. 8 for sample locations. The two samples at St Helens at the same distance were collected at different vertical positions within the deposit

ments result in similar relationships between mass loss and $R$. We know of no way to assess the comminution history of individual clasts. However, if comminution histories were highly variable we would expect to see different distributions of $R$ in the deposits from those in the lab. We have no evidence for such differences, and the standard deviation of $R$ for pumice in deposits is similar to that in the lab experiments.

The values of $R$ of $0.80-0.83$ for Lassen field pumice are reached after only a few percent mass loss. Thus, very little ash at Lassen was generated by comminution of large clasts. For the few percent mass loss we infer, breakup of larger clasts is also negligible in the lab. Because clast shape is so far from the steady value, this also means that the systematic decrease in clast size with distance (Eppler 1987) is not caused by comminution but by preferential deposition of the larger clasts.

The values of $R$ of $0.85-0.88$ for St Helens field pumice occur after $20-30 \%$ of mass loss. A couple of St Helens samples have $R$ similar to the steady state value in which case comminuted mass could exceed that at which the steady value of $R$ is reached.

The lack of significant changes in roundness with increasing distance is not a new finding. For example, Davies et al. (1978) found no change in sphericity in basalt clasts of the 1974 Fuego (Guatemala) glowing avalanche deposits, and only a very small increase in roundness at the distal end of the deposits where the avalanche was unconfined. Murai (1961) made a similar observation and offered two possible reasons for nearly uniform rounding. First, the breakage of particles to produce more angular fragments may counteract rounding so that a dynamicallydetermined steady roundness can be reached (Murai 1961; Dellino and Volpe 1996). In our laboratory experiments, this process may have limited the amount of rounding, especially for the Lassen pumice and to a lesser degree the Medicine Lake pumice samples. Second, there may be significant amounts of abrasion and breakup during transport to the vent (Dufek et al. in preparation); hence the initial roundness of the clasts preserved in a deposit may have varied over time if the fragmentation depth or eruption intensity changed over time (Murai 1961). In addition, much of the rounding may occur in the truly proximal regions where particle interactions in the collapsing columns are most frequent and energetic. This possibility can be addressed by study of deposits with well-preserved proximal deposits, within hundreds of meters of the vent. The deposits of the 1912 Novarupta, Alaska Plinian eruption may be a suitable candidate (Houghton et al. 2004).

We offer a different explanation, inspired by the numerical simulations of ash production presented in Dufek and Manga (2008). Ash production and consequent clast rounding occur in two different ways and each dominates in distinct regions of pyroclastic density currents. Collisional production of ash is greatest in the most energetic regionson steep slopes where density currents accelerate. At St Helens and Lassen, this region is the steep side of the main volcanic cone, closer to the vent than the locations where the clasts we measured were deposited (see Fig. 10). That is, much of the collisional rounding occurred well before the clasts arrived at the regions where they were deposited. Any subsequent rounding via collisions may have been minimal. The second way to generate ash and round clasts is via frictional interactions near the base of the flow. Most clasts that get deposited in an aggrading system must settle through a concentrated, near-bed region and clasts may experience similar amounts of abrasion before deposition. Clast deposition from en masse systems in levees and flow snouts are associated with concentrated flow and also are likely abraded by friction and numerous collisions during particle-dense transport.

In order to test this hypothesis we performed and present one representative numerical simulation in which we compute the location and rate of ash production for density currents that travel down a surface with a break in slope. The numerical approach is identical to that in Dufek and Manga (2008) and hence we refer readers to that paper for details about the governing equations and numerical methods. Briefly, all the phases of interest (gas, large pumice particles, ash) are treated as interpenetrating and interacting continua. Collisional energy and interactions are 


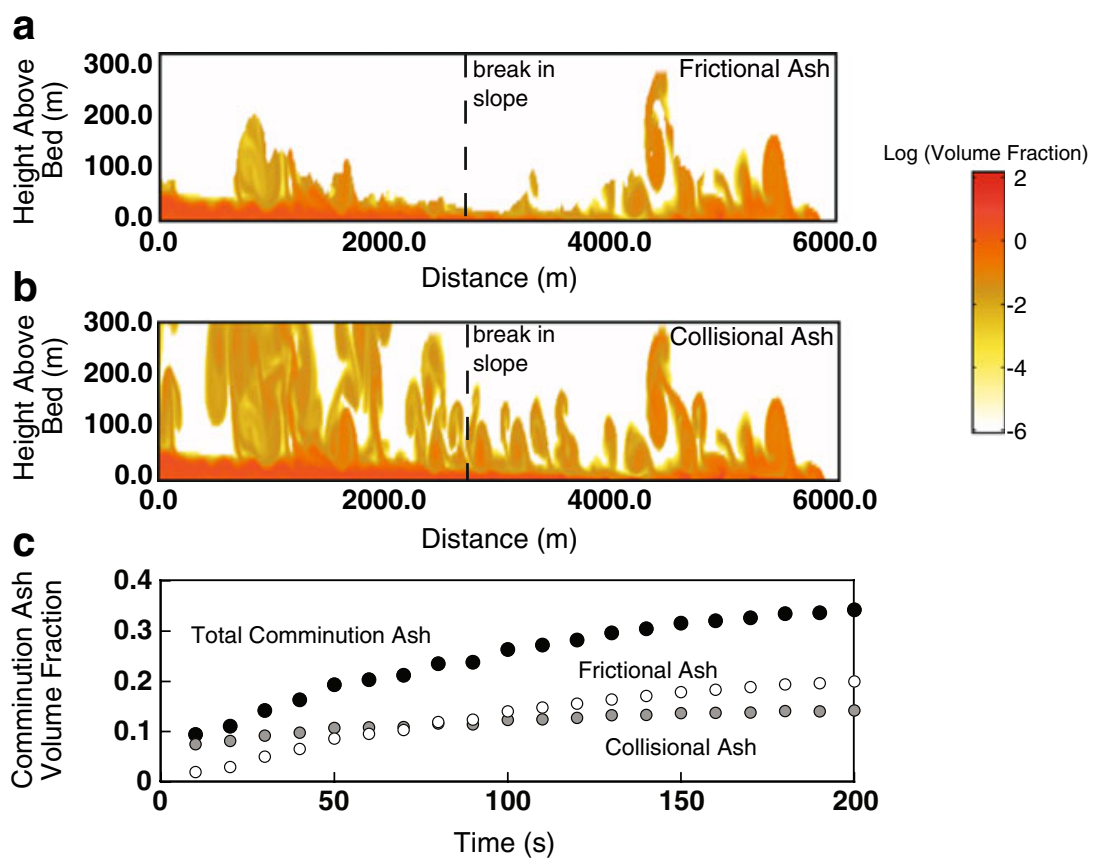

Fig. 12 An example result from numerical simulation of a pyroclastic density current showing the ash produced by $\mathbf{a}$ frictional and $\mathbf{b}$ collisional interactions. Details of the governing equations, numerical approach and experimentally-determined ash production rates are given in Dufek and Manga (2008). The density current enters from the left with an initial velocity of $50 \mathrm{~m} / \mathrm{s}$ and height of $100 \mathrm{~m}$. The current travels down a 25 degree slope and then onto level terrain (the break in slope is denoted by a dashed line in the figure.) Topography has been removed from these plots and the vertical axis is exaggerated to show the vertical structure of these currents. The current initially contains $1 \mathrm{~cm}$ pumice clasts with a density of $500 \mathrm{~kg} / \mathrm{m}^{3}$ and

reconstructed using kinetic theory (Dufek and Bergantz 2007). Ash production by particle collisions is based on the experimental measurements of Cagnoli and Manga (2003) and Dufek and Manga (2008); ash production by frictional interactions is based on the measurements of Cagnoli and Manga (2004).

Figure 12 shows the distribution of ash produced by comminution 100 seconds after the initiation of the density current. For this example, the density current travels down a slope of 25 degrees and then onto a flat surface, an approximation of the geometry and dimensions of Mount St Helens. Initially, the current consists of $1 \mathrm{~cm}$ pumice clasts (density $500 \mathrm{~kg} / \mathrm{m}^{3}$ and concentration of 1.25 volume percent) and equal volume fraction of 100 micron ash (density $2,000 \mathrm{~kg} / \mathrm{m}^{3}$ ). In Fig. 12, the volume fraction of particles is shown relative to the distance from the bed. That is, topography has been removed and the vertical axes are exaggerated to make the vertical structure apparent. The initial velocity is $50 \mathrm{~m} / \mathrm{s}$ and the initial height of the current is $100 \mathrm{~m}$. Ash produced by comminution has a 100 micron diameter and a density of $2,000 \mathrm{~kg} / \mathrm{m}^{3}$, properties identical to the ash originally present. The ash produced by comminution concentration of 1.25 volume percent. There is initially an ash phase present that is of equal volume percent (1.25) and is 100 micron in diameter with a density of $2,000 \mathrm{~kg} / \mathrm{m}^{3}$. Comminuted ash has a particle diameter of 100 microns and a density of $2,000 \mathrm{~kg} / \mathrm{m}^{3}$, identical to the ash present initially. However, the frictional and collisional ash are treated as distinct phases to record their spatial distribution. In these simulations the collisional ash comprises a greater fraction of ash in the secondary plumes, while a larger fraction of frictional ash remains with the body of the pyroclastic density current. c Total ash content as a function of time. In this example about $30 \%$ of the large clasts are comminuted into ash

(both by friction and collisions) is treated as a separate phase in order to distinguish between the ash originally present in the current and that produced by comminution. The ash production rate is much higher on the steep slopes where the flow is most energetic. Most of the collisionally produced ash occurs in the energetic head of the current while the frictionally produced ash occurs at the base along the entirety of the current. When the head of the current is on the steeper slope it accounts for a greater comminuted ash contribution compared to frictional ash. In this example, after the head reaches level terrain the situation reverses with a greater overall comminution contribution from frictional interactions. In this simulation mass was released continuously. Thus, the leveling-off of the mass fraction of ash after $100 \mathrm{~s}$, shown in Fig. 12c, occurs because most of the mass has traveled past the break in slope and hence past the region with the greatest ash production rate. In this example just over $30 \%$ of the large clasts are comminuted into ash, a value similar to that inferred from the roundness of the pumice clasts at St Helens.

Further numerical simulations using Lagrangian particles may refute or further validate some aspects of the hypothesis 
that most rounding occurs prior to clasts being transported to regions where deposition occurs. Measurements of the grainsize distribution of particles produced by comminution may also prove useful. It is also uncertain whether the lack of significant changes in $R$ with distance is a generic feature of all, or just some, deposits. Deposits with well-preserved proximal deposits may offer the best test.

\section{Concluding remarks}

As particles are transported and interact with each other and any substrate, they can break up or be abraded. The former process will produce angular particles, whereas the latter is expected to make clasts progressively more round. The final shape should reflect a balance between these processes. In our lab experiments we found that the shape of centimeter-size pumice clasts does evolve in a systematic way during comminution. Our adopted measure of shape, $R$ defined by Eq. 1, increases systematically from its initial value to a new steady value that is closer to the value of $R$ for a sphere. The steady value is reached after about $15 \%$ to $60 \%$ of the mass is lost. There is no obvious correlation between attributes of the clasts (e.g., presence of crystals) at the amount of mass loss needed to reach this steady shape, but this lack of correlation is based on analysis of pumice from only four different eruptions. The abrasion rate of clasts can vary by an order of magnitude, depending on the amount of abrasion and properties of the clasts. Crystal-rich clasts abrade more slowly than crystal-poor pumice. Over time, abrasion rates tend to decrease as clasts become more round. Owing to abrasion, pumice clasts transported in the dense, basal part of density currents are expected to lose mass at the rate of a few to a few tens of percent per kilometer of transport.

As with any measure of particle characteristics, such as grain size or sorting, complementary measurements or empirical and theoretical models are needed to make quantitative sense of the measurements. Here, for example, complementary laboratory studies of the relationship between shape and mass loss are required to estimate the fraction of mass lost by large clasts during transport. The field measurements of large clasts, when interpreted in the context of laboratory measurements of the evolution of clast shape, are consistent with numerical simulations (Dufek and Manga 2008) that predict a few to a few tens of percent mass loss from large clasts. The four pumice types we considered showed large enough variability in their relationships between mass lost and $R$ (Fig. 6) that the lab measurements may be necessary for quantitative assessment of mass lost based on clast shape. That is, to interpret clast shapes from a given eruption in the field, it may be necessary to perform rounding experiments in the lab using pumice from that eruption. Further experiments are needed to determine whether the conditions for particle interactions (e.g., impact velocity, particle concentration) affect the relationship between shape and mass loss.

Acknowledgements Supported by NSF grants 0809564 (AP and MM) and 0809321 (JD). We thank Max Rudolph for help at Lassen and St Helens. Rebecca Carey provided the Taupo samples and Ben Andrews assisted with making thin sections and took the SEM images. We thank C. Wilson, P. Dellino, G. Lube and J. White for many constructive suggestions and comments, but none should be held responsible for any interpretations in this paper.

Open Access This article is distributed under the terms of the Creative Commons Attribution Noncommercial License which permits any noncommercial use, distribution, and reproduction in any medium, provided the original author(s) and source are credited.

\section{References}

Barrett PJ (1980) The shape of rock particles, a critical review. Sedimentology 27:291-303

Bevilacqua P, Ferrara G (1996) Comminution of porous materials. Int J Miner Process 44-45:117-131

Cagnoli B, Manga M (2003) Pumice-pumice collisions and the effect of impact angle. Geophys Res Lett 30:1636. doi:10.1029/ 2003GL017421

Cagnoli B, Manga M (2004) Granular mass flows and Coulomb's friction in shear cell experiments: implications for geophysical flows. J Geophys Res 109:F04005. doi:10.1029/2004JF000177

Calder ES, Sparks RSJ, Gardeweg MC (2000) Erosion, transport and segregation of pumice and lithic clasts in pyroclastic flows inferred from ignimbrite at Lascar Volcano, Chile. J Volcanol Geotherm Res 104:201-235

Carey S, Maria A, Sigurdsson H (2000) Use of fractal analysis for discrimination of particles from primary and reworked jokulhlaup deposits in SE Iceland. J Volcanol Geotherm Res 161:234-246

Christiansen RL, Clynne MA, Muffler LJP (2002) Geologic map of the Lassen Peak, Chaos Crags, and Upper Hat Creek area, California. USGS Geological Investigations Series I-2723

Clynne MA (1999) A complex magma mixing origin for rocks erupted in 1915, Lassen Peak, California. J Petrol 40:105132

Criswell CW (1987) Chronology and pyroclastic stratigraphy on the May 18, 1980, eruptions of Mount St. Helens, Washington. J Geophys Res 92(10):237-10, 266

Davies DL, Quearry MW, Bonis SB (1978) Glowing avalanches from the 1974 eruption of the volcano Fuego, Guatemala. Geol Soc Am Bull 89:369-384

Dellino P, La Volpe L (1995) Fragmentation versus transportation mechanisms in the pyroclastic sequence of Monte Pilato-Rocche Rosse (Liapri, Italy). J Volcanol Geotherm Res 64:211-232

Dellino P, Liotino G (2002) The fractal and multifractal dimension of volcanic ash particles contout: a test study on the utility and volcanological relevance. J Volcanol Geotherm Res 113:1-18

Dellino P, Volpe LL (1996) Image processing analysis in reconstructing fragmentation and transportation mechanisms of pyroclastic deposits. The case of Monte Pilato-Rocche Rosse eruptions, Lipari (Aeolian islands, Italy). J Volcanol Geotherm Res 71:13-29 
Dufek J, Bergantz GW (2007) The suspended-load and bed-load transport of particle laden gravity currents: insight from pyroclastic flows that traverse water. Theor Comput Fluid Dyn 21:119-145

Dufek J, Manga M (2008) The in-situ generation of ash in pyroclastic flows. J Geophys Res 113:B09207. doi:10.1029/2007JB005555

Dufek J, Wexler J, Manga M (2009) The transport capacity of pyroclastic flows: experiments and models of substrate-flow interactions. J Geophys Res 114:B11203. doi:10.1029/2008JB006216

Durian DJ, Bideaud H, Duringer P, Schroder A, Marques CM (2007) The shape and erosion of pebbles. Phys Rev E 75:021301

Eppler DB (1987) The May 1915 eruptions of Lassen Peark, II: May 22 volcanic blast effects, sedimentology and stratigraphy of deposits, and characteristics of the blast cloud. J Volcanol Geotherm Res 31:65-85

Freundt A, Schmincke HU (1992) Abrasion in pyroclastic flows. Geol Rundsch 81:383-389

Hayakawa Y, Oguchi T (2005) Evaluation of gravel sphericity and roundness based on surface-area measurement with a laser scanner. Comput Geosci 31:735-741

Hobblitt RP, Miller CD, Vallance JW (1981) Origin and stratigraphy of the deposit produced by the May 18 directed blast, in the 1980 eruptions of Mount St. Helens, Washington. USGS Professional Paper 1250:401-419

Houghton BF, Wilson CJN, Fierstein J, Hildreth W (2004) Complex proximal deposition during the Plinian eruptions of 1912 at Novarupta, Alaska. Bull Volcanol 66:95-133

Krumbein WC (1941) Measurement and geological significance of shape and roundness of sedimentary particles. J Sed Petrol 11:64-72

Kuenen PH (1956) Experimental abrasion of pebbles 2. Rolling by current. J Geology 64:336-368

Kuenen PH (1959) Experimental abrasion 3. Fluviatile action of sand. Am J Science 257:172-190

Maria A, Carey S (2007) Quantitative discrimination of magma fragmentation and pyroclastic transport processes using the fractal spectrum technique. J Volcanol Geotherm Res 161:234-246
Murai I (1961) A study of the textural characteristics of pyroclastic flow deposits in Japan. Bulletin of the Earthquake Research Institute, Tokyo University 39:133-254

Orford JD, Whalley B (1983) The use of fractal dimension to quantify the morphology of irregular-shaped particles. Sedimentology 30:655-668

Pittari A, Cas RAF, Marti J (2005) The occurrence and origin of prominent massive pumice-rich ignimbrite lobes within the Late Pleistocene Abrigo Ignimbrite, Tenerife, Canary Islands. J Volcanol Geotherm Res 139:271-293

Powers MC (1953) A new roundness scale for sedimentary particles. J Sed Petrol 23:117-119

Putz C, Kueppers U, Dingwell DB (2010) Abrasion during pyroclastic density currents. abstract from 2010 EGU General Assembly Vienna: 11511

Roche O, Gilbertson MA, Phillips JC, Sparks RSJ (2005) Inviscid behaviour of fines-rich pyroclastic flows inferred fromexperiments on gas-particle mixtures. Earth Planet Sci Lett 240:401-414

Schwarcz HP, Shane KC (1969) Measurement of particle shape by Fourier analysis. Sedimentology 13:179-212

Schwarzkopf LM, Spieler O, Scheu B, Dingwell DB (2007) Fallexperiments on Merapi basaltic andesite and constraints on the generation of pyroclastic surges. eEarth $2: 1-5$

Shea T, Houghton BF, Gurioli L, Cashman KV, Hammer JE, Hobden BJ (2010) Textural studies of vesicles in volcanic rocks: an integrated methodology. J Volcanol Geotherm Res 190:271-289

Taddeucci J, Palladino DM (2002) Particle size-density relationships in pyroclastic deposits: inferences for emplacement processes. Bull Volcanol 64:273-284

Wadell H (1932) Volume, shape, and roundness of rock particles. J Geol 40:443-451

Walker GPL (1981) Generation and dispersal of fine ash and dust by volcanic eruptions. J Volcanol Geotherm Res 11:81-92

Wilson CJL, Hildreth W (1998) Hybrid fall deposits in the Bishop Tuff, California: a novel pyroclastic depositional mechanism. Geology 16:7-10 